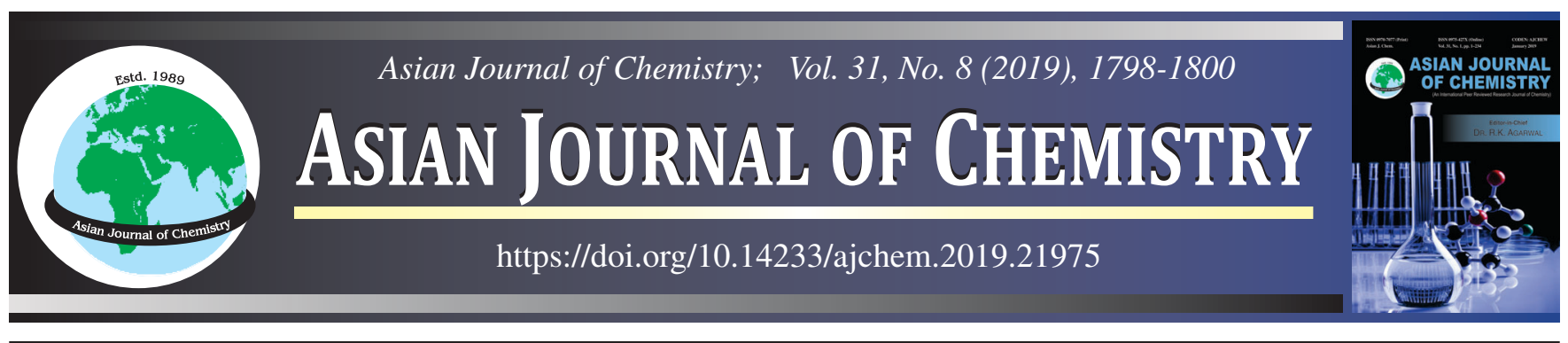

\title{
Poly(ethylene glycol) Supported Metal Nitrates as Well-Organized Reagents for Hunsdiecker Conversion of $\alpha, \beta$-Unsaturated Acids to $\beta$-Nitrostyrenes under Solvent and Acid-Free Conditions
}

K. RAmesh ${ }^{1}$, S. Shylaja ${ }^{1}$, S. Ramgopal ${ }^{2}$, A. SAmbashiva RaO ${ }^{3}$ and K.C. RaJANna ${ }^{2, *}$

${ }^{1}$ Department of Chemistry, Chaitanya Bharathi Institute of Technology, Gandipet, Hyderabad-500075, India

${ }^{2}$ Department of Chemistry, Osmania University, Hyderabad-500001, India

${ }^{3}$ Department of Chemistry, M.V.S.R. Engineering College, Hyderabad-501510, India

*Corresponding author: E-mail: kcrajannaou@yahoo.com

Received: 2 February 2019;

Accepted: 9 April 2019;

Published online: 28 June 2019;

AJC-19454

Poly(ethylene glycol) (PEG) supported metal nitrates such as ferric nitrate and manganese nitrate were accomplished as well-organized reagents for Hunsdiecker conversion of $\alpha, \beta$-unsaturated acids to $\beta$-nitrostyrenes under acid-free and solvent free conditions using grindstone technique. However, in the case of unsaturated aliphatic acids, nitro alkene derivatives were obtained as products. PEG-400 was found the best among the other PEGs (PEG-200,300, 400, 600, 3000 and 6000) used in this protocol.

Keywords: PEG supported metal nitrates, $\beta$-Nitrostyrenes, $\alpha, \beta$-Unsaturated acids, Hunsdiecker conversion.

ᄂ - - - - - - - - - - - - - - - - - - - - - - - - - - - - - - - -

\section{INTRODUCTION}

Solvent and acid free organic synthesis captured the attention of chemistry community all over the world because of their importance to prevent environmental pollution, improve green reaction conditions followed by enhanced selectivity [1-11]. Stimulated by these striking features coupled with other green-chemistry principles we too have focused our attention to design, improve and execute green synthetic protocols [1220]. In previous publication [19] we reported the synthesis of $\beta$-nitrostyrenes and nitroalkenes respectively from $\alpha, \beta$ unsaturated aromatic and aliphatic acids using metal nitrates and few drops of $\mathrm{HNO}_{3}$ by grinding all the ingredients in a mortar with a pestle. In another publication [20], we have explored poly(ethylene glycols) (PEGs) as efficient catalysts in these reactions under acid-free conditions. Recent literature reports revealed that PEGs are cost-effective and user-friendly additives/solvents to enhance and facilitate several organic transformations [21-27]. Enthused by these results we have tried to further improve the greenery of the reactions. In this part of the work, we have employed PEGs (PEG-200,300, 400, 600, 3000 and 6000) as additives along with $d$-block metal nitrates like $\mathrm{Fe}(\mathrm{III})$ and $\mathrm{Mn}$ (II) nitrates under acid-free and solvent free conditions.

\section{EXPERIMENTAL}

Grind-stone method of $\boldsymbol{\beta}$-nitro styrene synthesis: Known amounts of unsaturated acid ( $0.1 \mathrm{~mol}), \mathrm{PEG}(0.02 \mathrm{~mol})$ and Fe(III) or $\mathrm{Mn}(\mathrm{II})$ nitrate $(\mathrm{O} .12 \mathrm{~mol})$ were taken in a mortar and ground with a pestle till the reaction mixture became homogeneous. After completion of the reaction, as confirmed by TLC, about $2 \% \mathrm{Na}_{2} \mathrm{CO}_{3}$ solution was added to the reaction mixture till it is neutralized. Reaction product was extracted by dichloromethane (DCM) or dichloroethane (DCE), dried with sodium sulfate and purified by column chromatography. Binary solvent mixture of ethyl acetate and hexane (3:7) was used as eluent to obtain pure product.

\section{RESULTS AND DISCUSSION}

All the reactants $(\alpha, \beta$-unsaturated acid, PEG and metal nitrate) are taken in a clean mortar and ground with a pestle till the reaction is completed, as ascertained by TLC. The reactions with aromatic carboxylic acid such as cinnamic acid afforded $\beta$ nitro styrenes, while the aliphatic carboxylic acid such as crotonic acid afforded nitroalkenes in good yield of products with high regioselectivity. Initially the reactions are conducted with cinnamic acid, metal nitrate and different PEGs are to select the best PEG. The observed results are presented in Table-1.

This is an open access journal, and articles are distributed under the terms of the Attribution 4.0 International (CC BY 4.0) License. This license lets others distribute, remix, tweak, and build upon your work, even commercially, as long as they credit the author for the original creation. You must give appropriate credit, provide a link to the license, and indicate if changes were made. 


\begin{tabular}{|c|c|c|c|c|}
\hline \multicolumn{5}{|c|}{$\begin{array}{c}\text { TABLE-1 } \\
\text { EFFECT OF ADDITIVE PEG ON METAL NITRATE MEDIATED } \\
\text { NITRO DECARBOXYLATION OF CINNAMIC ACID } \\
\text { UNDER SOLVENT FREE CONDITIONS }\end{array}$} \\
\hline \multirow{2}{*}{ Entry } & \multicolumn{2}{|c|}{$\mathrm{Fe}\left(\mathrm{NO}_{3}\right)_{3}$} & \multicolumn{2}{|c|}{$\mathrm{Mn}\left(\mathrm{NO}_{3}\right)_{2}$} \\
\hline & Time (min) & Yield (\%) & Time (min) & Yield $(\%)$ \\
\hline PEG-200 & 45 & 90 & 45 & 88 \\
\hline PEG-300 & 60 & 86 & 60 & 83 \\
\hline PEG-400 & 30 & 88 & 30 & 87 \\
\hline PEG-600 & 30 & 86 & 30 & 85 \\
\hline PEG-3000 & 60 & 76 & 60 & 80 \\
\hline PEG-6000 & 35 & 88 & 30 & 87 \\
\hline
\end{tabular}

The products were characterized by ${ }^{1} \mathrm{H}$ NMR, mass spectra and physical data with authentic samples and found to agree well with earlier reports [25,27].

$\boldsymbol{\beta}$-Nitro styrene: Mass: $(\mathrm{m} / \mathrm{z}) 149 ;{ }^{1} \mathrm{H}$ NMR: $\delta 6.4(\mathrm{~d} 1 \mathrm{H}$, $\beta-\mathrm{CH}), \delta$ 7.3-7.65 (m 5H, Ar-H) $\delta 7.8$ (d 1H, $\alpha-\mathrm{CH})$.

1-Nitro propene: Mass: $(\mathrm{m} / z) 87 ;{ }^{1} \mathrm{H}$ NMR: $\delta 2.12(\mathrm{~d}$ $\left.3 \mathrm{H}, \mathrm{CH}_{3}\right), \delta 7.0$ (d 1H, $\left.\alpha-\mathrm{CH}\right), \delta 7.15(\mathrm{~m} \mathrm{1H}, \beta-\mathrm{CH})$.

Effect of PEG and metal nitrate on the reactivity: The results (Table-1) show that the reactions afford very good to excellent yields within $1 \mathrm{~h}$ when the reactants are ground in a mortar with a pestle, in presence of laboratory desk top $d$-block metal nitrates such as ferric nitrate and manganese nitrate. Further, the reactions underwent smoothly with all the poly(ethylene glycols) (molecular weights ranging from PEG200 to PEG-6000). However, among the different PEGs used in the present study, PEG-400 has been found to be much more effective than other PEGs. It is evident that due to the grinding of reactants in a mortar with a pestle, mechanical energy is converted to heat energy, which could be utilized for activation of molecules. Since the grinding is done under solvent free conditions, bulk and speedy activation of molecules can be expected. Majority of such activated molecules might undergo chemical change and afford products in good to excellent yields. Basically poly(ethylene glycol) is an alcohol which is capable of binding with transition metal nitrates such as Fe(III) nitrate and $\mathrm{Mn}(\mathrm{II})$ nitrate to form to give $\left[\mathrm{M}\left(\mathrm{NO}_{3}\right)_{\mathrm{x}-1}(\mathrm{PEG})\right]$, a ternary complex containing PEG in the metal coordination spheres. The complex thus formed is as an effective catalyst to trigger the nitration reaction through the generation of active nitronium ion as shown in Scheme-I.

Effect of structure on reactivity: The results (Table-2) revealed that the reaction is sensitive to the structural variation of cinnamic acid, when the nitro decarboxylation reaction is conducted with cinnamic acids in presence of PEG-400 and metal nitrates reaction rates accelerated with the introduction of electron donating groups and retarded with electron withdrawing groups.

\section{Conclusion}

In summary, we have accomplished poly(ethylene glycol) supported $\mathrm{Fe}$ (III) nitrate and $\mathrm{Mn}$ (III) nitrate as efficient reagents for the synthesis of $\beta$-nitro styrenes from $\alpha, \beta$-unsaturated carboxylic acids under solvent-free and mineral acid-free conditions using cost-effective grind-stone technology. The

$$
\begin{aligned}
& \mathrm{H}-\left(\mathrm{OCH}_{2}-\mathrm{CH}_{2}\right)_{\mathrm{n}}-\mathrm{OH}+\left[\mathrm{M}\left(\mathrm{NO}_{3}\right)_{\mathrm{x}}\right] \stackrel{\mathrm{K}}{\rightleftharpoons}\left[\mathrm{H}-\left(\mathrm{OCH}_{2}-\mathrm{CH}_{2}\right)_{\mathrm{n}}-\mathrm{O}-\mathrm{M}\left(\mathrm{NO}_{3}\right)_{\mathrm{x}-1}\right]+\mathrm{HNO}_{3} \\
& \text { (PEG) } \\
& \text { (Metal nitrate) } \\
& \text { [PEG-Metal nitrate] }
\end{aligned}
$$

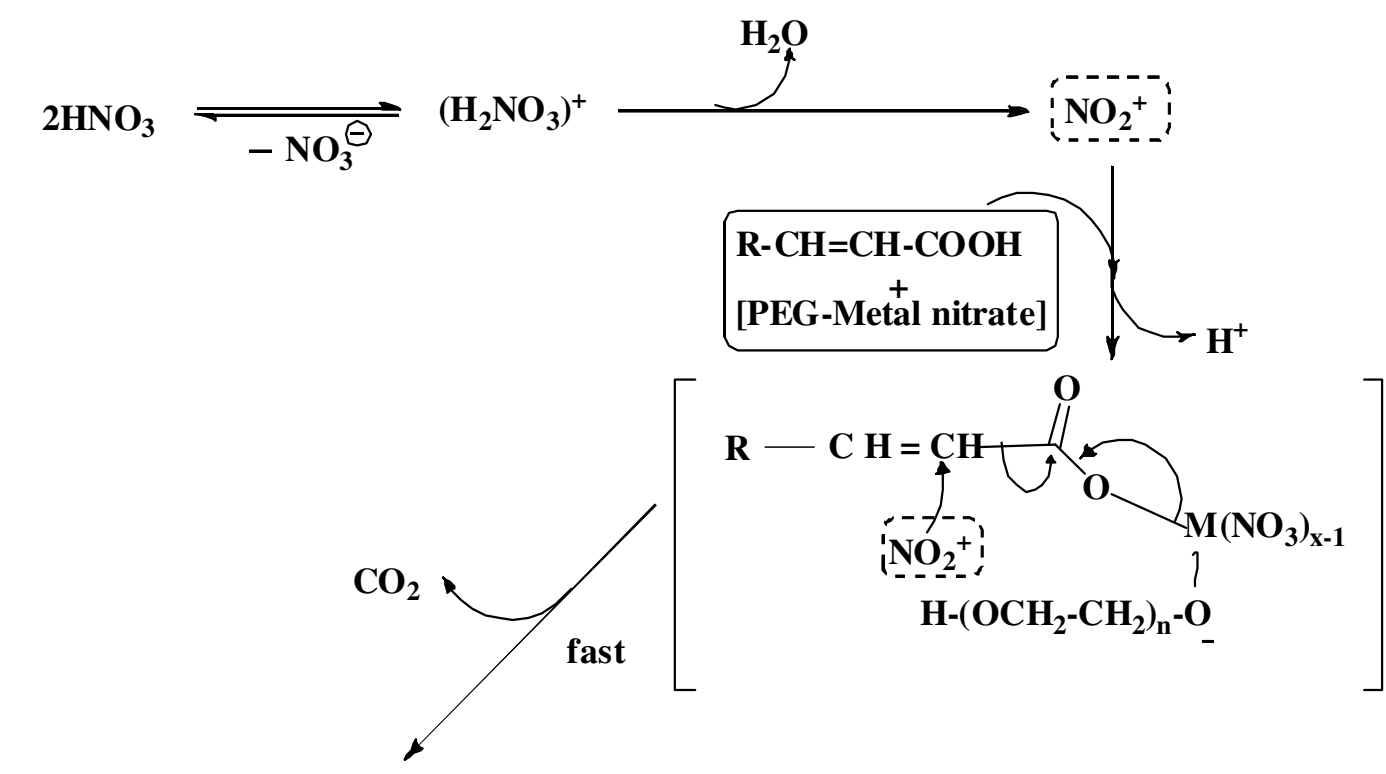

$$
\begin{gathered}
{\left[\mathrm{H}-\left(\mathrm{OCH}_{2}-\mathrm{CH}_{2}\right)_{\mathrm{n}}-\mathrm{O}-\mathrm{M}\left(\mathrm{NO}_{3}\right)_{\mathrm{x}-1}\right]} \\
{\left[\mathrm{H}-\left(\mathrm{OCH}_{2}-\mathrm{CH}_{2}\right)_{\mathrm{n}}-\mathrm{O}-\mathrm{M}\left(\mathrm{NO}_{3}\right)_{\mathrm{x}-1}\right]}
\end{gathered}
$$

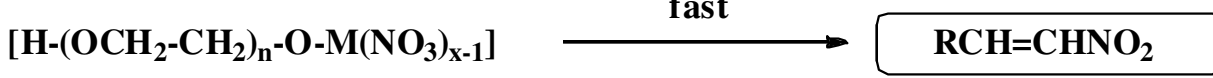

Scheme-I: Plausuble mechanism of nitrodecarboxylation of unsaturated acid 


\begin{tabular}{lcc|cc}
\hline \multicolumn{5}{c}{ TABLE-2 } \\
NITRO DECARBOXYLATION OF CINNAMIC ACIDS IN \\
PRESENCE OF PEG-400 AND METAL NITRATES \\
\multicolumn{4}{c}{ UNDER SOLVENT FREE CONDITIONS } \\
\hline \multicolumn{2}{c}{ Entry $\left(\mathrm{NO}_{3}\right)_{3}$} & \multicolumn{2}{c}{ Mn $\left(\mathrm{NO}_{3}\right)_{2}$} \\
\cline { 2 - 5 } & Time & Yield & Time & Yield \\
& $(\mathrm{min})$ & $(\%)$ & $(\mathrm{min})$ & $(\%)$ \\
\hline Cinnamic acid & 30 & 88 & 30 & 87 \\
4-Chloro cinnamic acid & 60 & 86 & 60 & 83 \\
4-Methoxy cinnamic acid & 30 & 88 & 30 & 87 \\
4-Methyl cinnamic acid & 30 & 86 & 30 & 85 \\
4-Nitro cinnamic acid & 60 & 76 & 60 & 80 \\
4-Hydroxy cinnamic acid & 30 & 92 & 30 & 88 \\
Acrylic acid & 30 & 80 & 30 & 78 \\
Crotonic acid & 60 & 78 & 60 & 78 \\
3-Phenyl crotonic acid & 30 & 76 & 30 & 80 \\
2-Chloro cinnamic acid & 60 & 82 & 60 & 70 \\
2-Methyl cinnamic acid & 30 & 86 & 30 & 78 \\
\hline
\end{tabular}

reactants were ground in a mortar with a pestle till the reaction is completed. The reaction time is generally about $30-60 \mathrm{~min}$. The present finding has advantages such as the use of economically cheap and readily available desktop Fe(III) and Mn(III) nitrates, PEGs and unsaturated acids.

\section{CONFLICT OF INTEREST}

The authors declare that there is no conflict of interests regarding the publication of this article.

\section{REFERENCES}

1. P. Anastas and J. Warner, Green Chemistry: Theory and Practice, Oxford University Press: New York (1998).

2. L.E. Kaïm, L. Gautier, L. Grimaud, L.M. Harwood and V. Michaut, Green Chem., 5, 477 (2003); https://doi.org/10.1039/B306242B.

3. G.R. Desiraju and B.S. Goud, ed.: V.V. Boldyrev, Reactivity of Solids: Present, Past and Future, Blackwell Sciences: London, p. 223 (1995).

4. K. Tanaka and F. Toda, Chem. Rev., 100, 1025 (2000); https://doi.org/10.1021/cr940089p.

5. G.W.V. Cave, C.L. Raston and J.L. Scott, Chem. Commun., 2159 (2001); https://doi.org/10.1039/b106677n.

6. I. Mohammadpoor-Baltork, M. Sadeghi and A.-H. Adibi, Molecules, 6, 900 (2001); https://doi.org/10.3390/61100900.
7. J.D. Lou and Z.N. Xu, Tetrahedron Lett., 43, 6095 (2002); https://doi.org/10.1016/S0040-4039(02)01333-3.

8. J.D. Lou and Z.N. Xu, Tetrahedron Lett., 43, 8843 (2002); https://doi.org/10.1016/S0040-4039(02)02234-7.

9. J.D. Lou and Z.N. Xu, Tetrahedron Lett., 43, 6149 (2002); https://doi.org/10.1016/S0040-4039(02)01345-X.

10. J.L. Scott, D.R. MacFarlane, C.L. Raston and M. Teoh, Green Chem., 2, 123 (2000); https://doi.org/10.1039/b000825g.

11. C.L. Raston and J.L. Scott, Green Chem., 2, 49 (2000); https://doi.org/10.1039/a907688c

12. M.M. Ali, K.C. Rajanna and P.K. Sai Prakash, Synlett, 2001, 251 (2001); https://doi.org/10.1055/s-2001-10765.

13. M.M. Ali, S. Sana, Tasneem, K.C. Rajanna and P.K. Saiprakash, Synth. Commun., 32, 1351 (2002); https://doi.org/10.1081/SCC-120003631.

14. K.C. Rajanna, M. Moazzam Ali, S. Sana, Tasneem and P.K. Saiprakash, J. Dispers. Sci. Technol., 25, 17 (2004); https://doi.org/10.1081/DIS-120027663.

15. K.C. Rajanna, M.M. Ali, S. Sana and P.K. Saiprakash, Chem. Lett., 1, 48 (2000).

16. C. Hunsdiecker and H. Hunsdiecker, Ber. Dtsch. Chem. Ges., 75, 291 (1942); https://doi.org/10.1002/cber.19420750309.

17. R.G. Johnson and R.K. Ingham, Chem. Rev., 56, 219 (1956); https://doi.org/10.1021/cr50008a002.

18. A.G. Smith, Organic Synthesis, Wiley Interscience: New York (1993).

19. S. Ramgopal, K. Ramesh, A. Chakradhar, N.M. Reddy and K.C. Rajanna, Tetrahedron Lett., 48, 4043 (2007); https://doi.org/10.1016/j.tetlet.2007.04.026.

20. K.C. Rajanna, K. Ramesh, S. Ramgopal, S. Shylaja, P.G. Reddy and P.K. Saiprakash, Green. Sustain. Chem., 1, 132 (2011); https://doi.org/10.4236/gsc.2011.14022.

21. T.J. Dickerson, N.N. Reed and K.D. Janda, Chem. Rev., 102, 3325 (2002); https://doi.org/10.1021/cr010335e.

22. B. Das, V.S. Reddy and M. Krishnaiah, Tetrahedron Lett., 47, 8471 (2006); https://doi.org/10.1016/i.tetlet.2006.09.153.

23. S. Chandrasekhar, N.R. Reddy, S.S. Sultana, Ch. Narsihmulu and K.V. Reddy, Tetrahedron, 62, 338 (2006); https://doi.org/10.1016/j.tet.2005.09.122.

24. J.-H. Li, X.-C. Hu, Y. Liang and Y.-X. Xie, Tetrahedron, 62, 31 (2006); https://doi.org/10.1016/j.tet.2005.09.138

25. S. Chandrasekhar, C. Narsihmulu, B. Saritha and S.S. Sultana, Tetrahedron Lett., 45, 5865 (2004); https://doi.org/10.1016/j.tetlet.2004.05.153.f

26. B. Das, M. Krishnaiah, P. Thirupathi and K. Laxminarayana, Tetrahedron Lett., 48, 4263 (2007); https://doi.org/10.1016/j.tetlet.2007.04.062.

27. A.I. Vogel, Text Book of Practical Organic Chemistry, Longman: London and New York, edn 4 (1986). 